\title{
Enzymatic degradation of sulfite-pulped softwoods and the role of LPMOs
}

\author{
Piotr Chylenski ', Dejan M. Petrović1, Gerdt Müller' ${ }^{1}$, Marie Dahlström², Oskar Bengtsson², Martin Lersch², \\ Matti Siika-aho ${ }^{3}$, Svein Jarle Horn ${ }^{1}$ and Vincent G. H. Eijsink ${ }^{1 *}$
}

\begin{abstract}
Background: Recent advances in the development of enzyme cocktails for degradation of lignocellulosic biomass, especially the discovery of lytic polysaccharide monooxygenases (LPMOs), have opened new perspectives for process design and optimization. Softwood biomass is an abundant resource in many parts of the world, including Scandinavia, but efficient pretreatment and subsequent enzymatic hydrolysis of softwoods are challenging. Sulfite pulping-based pretreatments, such as in the BALI ${ }^{\mathrm{TM}}$ process, yield substrates that are relatively easy to degrade. We have assessed how process conditions affect the efficiency of modern cellulase preparations in processing of such substrates.

Results: We show that efficient degradation of sulfite-pulped softwoods with modern, LPMO-containing cellulase preparations requires the use of conditions that promote LPMO activity, notably the presence of molecular oxygen and sufficient reducing power. Under LPMO activity-promoting conditions, glucan conversion after 48-h incubation with Cellic ${ }^{\circledR}$ CTec3 reached 73.7 and $84.3 \%$ for Norway spruce and loblolly pine, respectively, at an enzyme loading of $8 \mathrm{mg} / \mathrm{g}$ of glucan. The presence of free sulfite ions had a negative effect on hydrolysis efficiency. Lignosulfonates, produced from lignin during sulfite pretreatment, showed a potential to activate LPMOs. Spiking of Celluclast ${ }^{\circledR}$, a cellulase cocktail with low LPMO activity, with monocomponent cellulases or an LPMO showed that the addition of the LPMO was clearly more beneficial than the addition of any classical cellulase. Addition of the LPMO in reactions with spruce increased the saccharification yield from approximately $60 \%$ to the levels obtained with Cellic ${ }^{\circledR} \mathrm{CTec} 3$.

Conclusions: In this study, we have demonstrated the importance of LPMOs for efficient enzymatic degradation of sulfite-pulped softwood. We have also shown that to exploit the full potential of LPMO-rich cellulase preparations, conditions promoting LPMO activity, in particular the presence of oxygen and reducing equivalents are necessary, as is removal of residual sulfite from the pretreatment step. The use of lignosulfonates as reductants may reduce the costs related to the addition of small molecule reductants in sulfite pretreatment-based biorefineries.
\end{abstract}

Keywords: Lignocellulose, Sulfite, Pretreatment, Pulping, Cellulase, LPMO, AA9, GH61, Biofuel

\section{Background}

Enzymatic degradation of lignocellulose plays a pivotal role in a future biomass-based economy. Woody biomass is a sustainable source of lignocellulosic biomass in many parts of the world, including Scandinavian countries, North and South America, and New Zealand, and its efficient biochemical conversion is of major importance

\footnotetext{
*Correspondence: vincent.eijsink@nmbu.no

${ }^{1}$ Faculty of Chemistry, Biotechnology and Food Science, Norwegian

University of Life Sciences, P.O. Box 5003, 1432 Ås, Norway

Full list of author information is available at the end of the article
}

for the transition toward a biomass-based economy [1]. Recalcitrance of lignocellulosic biomass is one of the key factors hampering commercialization of plant biomassderived fuels and chemicals and woody biomass is particularly challenging due to its physical properties, such as a dense structure and a high lignin content $[1,2]$. To overcome biomass recalcitrance, various pretreatment technologies have been introduced. Pretreatments for woody biomass include steam explosion (usually acid-catalyzed), dilute acid, organosolv, and sulfite-pretreatment-to-overcome-recalcitrance-of-lignocellulose 
(SPORL). Generally, pretreatment and subsequent enzymatic digestion of hardwoods is less demanding compared to softwoods, which contain more lignin and have more rigid structure $[1,3]$. Relatively efficient pretreatment and enzymatic hydrolysis of softwoods has been demonstrated for organosolv- and SPORL-pretreated biomasses $[4,5]$. The $\mathrm{BALI}^{\mathrm{TM}}$ process is an alternative sulfite-based pretreatment that yields cellulose-rich substrates containing little lignin and hemicellulose relative to, e.g., the SPORL pretreatment, whose enzymatic conversion to glucose is relatively easy [6].

Complete biochemical conversion of cellulose to monomeric sugars requires the synergistic action of several classes of enzymes [7]. By far, the most studied enzymes are cellulose-degrading glycoside hydrolases, known as cellulases. Cellulases include enzymes acting on the ends of the cellulose chain, known as cellulose $1,4-\beta$-cellobiosidases or cellobiohydrolases, cleaving off cellobiose units from reducing and non-reducing chain ends. Endo- $\beta$-1,4-glucanases cleave internal glycosidic bonds in the cellulose chains, thus generating novel chain ends, and $\beta$-glucosidases convert released soluble cellodextrins and cellobiose to glucose [8]. In natural biomass-converting enzyme systems, the cellulases are accompanied by a wide range of hemicellulose- and lignin-degrading enzymes working in concert to fully decompose lignocellulose.

The discovery of lytic polysaccharide monooxygenases (LPMOs) has challenged the classical model of enzymatic decomposition of polysaccharides. Contrary to cellulases, which rely on hydrolysis to perform catalysis, LPMOs are metalloenzymes breaking down glycosidic bonds by an oxidative mechanism involving molecular oxygen (or, in a recently suggested alternative mechanism, hydrogen peroxide [9]) and an electron donor [10, 11]. LPMO-catalyzed cleavage of the glycosidic bond results in the formation of oxidized chain ends, either at the $\mathrm{C} 1$ and/or at the C4 carbon position. So far, LPMOs cleaving glycosidic bonds in chitin $[10,12]$, cellulose $[11,13-16]$, cellooligosaccharides [17], hemicellulose [18, 19], and starch $[20,21]$ have been identified. LPMOs are classified in the Carbohydrate Active Enzymes (CAZy) database as auxiliary activities families AA9, AA10, AA11, and AA13 [22].

Despite the fact that the boosting effect of LPMOs on cellulase activity was demonstrated early on $[13,15]$, exploration of the role and performance of LPMOs in applied settings has been limited. Cannella et al. [23] showed that LPMOs present in the commercial cellulase preparation Cellic ${ }^{\circledR}$ CTec2 enhanced hydrolysis of hydrothermally pretreated wheat straw. Müller and colleagues showed the importance of LPMOs in this enzyme preparation for degradation of steam-exploded birch [24]. Using both model cellulosic substrates and industrially relevant lignocellulosic biomass, $\mathrm{Hu}$ et al. [25] demonstrated synergy between AA9 LPMOs and cellulases.

In this study, we have investigated the impact of process conditions on the enzymatic degradation of sulfitepulped softwood biomasses with particular focus on the role of LPMOs, the presence of oxygen and small molecule electron donors, and the effect of residual sulfite. We have utilized commercially available cellulase preparations, Celluclast ${ }^{\circledR} 1.5 \mathrm{~L}$ (supplemented with Novozym 188) and Cellic ${ }^{\circledR}$ CTec3, as well as an in-house produced fungal LPMO from Thermoascus aurantiacus (TaLPMO9A) and individual major Trichoderma reesei cellulases.

\section{Methods}

\section{Cellulosic substrates, pretreatment, and compositional} analysis

Norway spruce (Picea abies) and loblolly pine (Pinus taeda) were subjected to the proprietary pretreatment technology developed by Borregaard AS (Sarpsborg, Norway) [6, 26]. The pretreatment included a sulfite cooking step utilizing calcium or sodium as a counterion, which converts lignin into water-soluble lignosulfonates and removes most of the hemicellulose that is washed out of the remaining cellulose pulp. The composition of the pretreated materials was determined following the National Renewable Energy Laboratory standardized protocol (NREL/TP-510-42618) and is presented in Table 1 . The commercially available model cellulosic substrate Avicel PH-101 (Sigma Aldrich, St. Louis, MO, USA) was also used in enzymatic hydrolysis experiments. Dried lignosulfonates were kindly provided by Borregaard AS (Norway, Sarpsborg) and were obtained by the evaporation of the sulfite spent liquor (SSL) that had been stripped of soluble sugars by fermentation [6].

\section{Enzymes}

Celluclast $^{\circledR}$ 1.5L, Novozym 188, and Cellic ${ }^{\circledR}$ CTec3 were all kindly provided by Novozymes A/S (Bagsværd,

Table 1 Compositional analysis of pretreated Norway spruce and Loblolly pine

\begin{tabular}{lllll}
\hline Substrate & \multicolumn{4}{l}{ Component (\% of DM) } \\
\cline { 2 - 5 } & Glucan $^{\mathbf{b}}$ & Xylan $^{\mathbf{b}}$ & Mannan $^{\mathbf{b}}$ & Acid insoluble lignin \\
\hline Norway spruce & 88.3 & 4.5 & 4.8 & 3.8 \\
Loblolly pine & 80.4 & 3.0 & 3.0 & 8.9 \\
Avicel & 92.2 & 2.1 & 0.1 & 0.9
\end{tabular}

Values are presented as a percentage of dry matter

a The presence of the potentially inhibitory sugar derivatives furfural and hydroxymethylfurfural was also analyzed; both were not detected

b Sugar monomers measured by HPLC and corrected by the hydration factor $\left({ }^{*} 0.9\right)$

c Klason lignin (not corrected for ash) 
Denmark). The AA9 family LPMO from Neurospora crassa (NcLPMO9C), used for generation of $\mathrm{C} 4$ oxidized standards, was produced and purified as described previously [24]. Trichoderma reesei Cel7A was purified from the culture filtrate of $T$. reesei QM 9414 (VTT Culture Collection, D-74075, Finland) essentially as described in [27]. $\operatorname{TrCel7B}$ and $\operatorname{TrCel6A}$ from $T$. reesei were purified as described by Suurnäkki et al. [28].

The gene encoding $T$. aurantiacus LPMO9A (also known as TaGH61A; [11]) including its native signal sequence was codon optimized for Pichia pastoris (GenScript, Piscataway, NJ, USA). A synthetic, Pichiaoptimized gene encoding TaLPMO9A was excised from the pUC57 vector using Acc65I and EcoRI restriction enzymes (New England BioLabs [NEB] Inc, MA, USA) and ligated into the same sites of the pPINK-GAP vector [29], yielding the pPINK-GAP_TaLPMO9A plasmid. This plasmid was then linearized with AflII and $5 \mu \mathrm{g}$ of linearized plasmid was transformed into freshly prepared electrocompetent $P$. pastoris PichiaPink $^{\mathrm{TM}}$ Strain 4 cells, following the manufacturer's instructions (Thermo Fisher Scientific, Waltham, MA, USA), using a Bio-Rad Gene Pulser II electroporation system (Bio-Rad Laboratories, Hercules, CA, USA) at $1.8 \mathrm{kV}, 25 \mu \mathrm{F}$, and 200 $\Omega$. Subsequently, the cells were incubated in $1 \mathrm{~mL}$ of YPDS medium for $2 \mathrm{~h}$ and spread on Pichia adenine dropout (PAD) selection plates (Thermo Fisher Scientific, Waltham, MA, USA), followed by incubation for 3-4 days at $30{ }^{\circ} \mathrm{C}$, until white colonies formed. Four colonies were picked and restreaked on fresh PAD plates. Overnight cultures of these four transformants were then screened for protein production in BMGY medium (containing $1 \%(\mathrm{v} / \mathrm{v})$ glycerol). A glycerol stock was prepared from an overnight culture of the best-producing transformant in BMGY medium by adjusting the cell suspension to $28 \%(\mathrm{v} / \mathrm{v})$ glycerol.

The best-producing transformant was grown in $20 \mathrm{~mL}$ of BMGY medium (containing $1 \%(\mathrm{v} / \mathrm{v})$ glycerol) in a 100 -mL shaken flask at $29^{\circ} \mathrm{C}$ and $200 \mathrm{rpm}$ for $16 \mathrm{~h}$. Subsequently, this pre-culture was used to inoculate $4 \times 0.5$ $\mathrm{L}$ of BMGY medium (containing 1\% (v/v) glycerol) in 2-L shaken flasks, followed by incubation at $29{ }^{\circ} \mathrm{C}$ and $200 \mathrm{rpm}$ for $48 \mathrm{~h}$. After $24 \mathrm{~h}$, the cultures were supplemented with $1 \%(\mathrm{v} / \mathrm{v})$ glycerol. The cells were harvested by centrifugation at $7.000 \mathrm{~g}$ for $15 \mathrm{~min}$, at $4{ }^{\circ} \mathrm{C}$. The supernatants were collected and dialyzed against $50 \mathrm{mM}$ BisTris buffer, $\mathrm{pH}$ 6.5, and concentrated to $150 \mathrm{~mL}$ using a VivaFlow 200 tangential crossflow concentrator (MWCO $10 \mathrm{kDa}$, Sartorius Stedim Biotech Gmbh, Germany). Ammonium sulfate was added to the concentrated supernatant to a final concentration of $1.42 \mathrm{M}$ after which the solution was loaded onto three linearly connected 5-mL HiTrap Phenyl FF columns (GE Healthcare
Life Sciences, Uppsala, Sweden) equilibrated with $50 \mathrm{mM}$ Bis-Tris buffer (pH 6.5), containing $1.42 \mathrm{M}$ ammonium sulfate. Proteins bound to the columns were eluted using a $75 \mathrm{~mL}$ linear gradient from 1.42 to $0 \mathrm{M}$ ammonium sulfate in $50 \mathrm{mM}$ Bis-Tris buffer ( $\mathrm{pH}$ 6.5), using a flow rate of $1 \mathrm{~mL} / \mathrm{min}$. Collected fractions were analyzed by sodium dodecyl sulfate polyacrylamide gel electrophoresis (SDS-PAGE), and the fractions containing TaLPMO9A were pooled and subsequently concentrated and buffer exchanged to $50 \mathrm{mM}$ Bis-Tris pH 6.5 using Amicon Ultra centrifugal filters (MWCO $10 \mathrm{kDa}$, Millipore).

Purified TaLPMO9A was saturated with $\mathrm{Cu}$ (II) by incubating the enzyme with an excess of $\mathrm{CuSO}_{4}$ (3:1 molar ratio of copper:enzyme) for $90 \mathrm{~min}$ at room temperature as described previously [30]. Subsequently, the protein solution was loaded onto a HiLoad 16/60 Superdex 75 size exclusion column (GE Healthcare Life Sciences, Uppsala, Sweden) in $50 \mathrm{mM}$ Bis-Tris buffer (pH 6.5), containing $150 \mathrm{mM} \mathrm{NaCl}$, using a flow rate of $0.75 \mathrm{~mL} / \mathrm{min}$. Fractions containing pure protein were identified using SDS-PAGE and subsequently pooled and concentrated using Amicon Ultra centrifugal filters (MWCO $10 \mathrm{kDa}$, Millipore).

To ensure full copper saturation, the purified LPMO was saturated once more with $\mathrm{Cu}$ (II), as described above. This time, after incubating the enzyme with $\mathrm{CuSO}_{4}$, the solution was loaded onto a PD midiTrap G-25 desalting column (GE Healthcare, UK), equilibrated with $20 \mathrm{mM}$ Bis-Tris buffer $\mathrm{pH}$ 6.0. Protein-containing fractions, eluted with $1 \mathrm{~mL}$ of equilibration buffer, were collected and stored at $4{ }^{\circ} \mathrm{C}$ until further use.

All protein concentrations were determined with the Bio-Rad modified Bradford method (Bio-Rad Laboratories, Hercules, CA, USA) utilizing bovine serum albumin (BSA) as a standard [31].

\section{Enzymatic hydrolysis}

Saccharification of lignocellulosic biomass and Avicel was conducted in 50-mL rubber sealed glass bottles (Wheaton, Millville, NJ, USA) with $10 \mathrm{~mL}$ working volume. The biomass obtained after the sulfite pulping process described above was not washed, milled, or dried prior to the saccharification experiments. Enzymatic hydrolysis was performed with $5 \%$ total solids loading in $50 \mathrm{mM}$ sodium acetate buffer $\mathrm{pH} 5.0$ at $50{ }^{\circ} \mathrm{C}$, with $8 \mathrm{mg} / \mathrm{g}$ glucan total protein loading of either a $5: 1(\mathrm{w} / \mathrm{w})$ Celluclast $^{\circledR}$ :Novozym 188 mixture or Cellic ${ }^{\circledR}$ CTec3, in the presence or absence of an external electron donor. To facilitate efficient mixing, bottles were rotated at $38 \mathrm{rpm}$ in a Multi RS-60 programmable rotator (Biosan, Riga, Latvia). Anaerobic conditions were reached by vigorously flushing the substrate-buffer suspension with nitrogen (Yara, Trondheim, Norway) for 3 min and addition 
of $0.025 \%(\mathrm{w} / \mathrm{v}$, final concentration) of L-cysteine hydrochloride monohydrate (Sigma Aldrich, St. Louis, MO, USA) to ensure complete removal of oxygen. In aerobic conditions, oxygen came from ambient air present in the headspace of the reaction bottles. Reactions were initiated by injection of $800 \mu \mathrm{L}$ of enzyme preparations, appropriately diluted in $50 \mathrm{mM}$ sodium acetate buffer $\mathrm{pH}$ 5.0, through the rubber septum. Reactions were terminated at different time points. To ensure reproducible sampling from the flasks, the entire reaction mixture was diluted threefold with ultrapure water (Merck Millipore, Billerica, MA, USA) and then transferred to new $50-\mathrm{mL}$ Falcon tubes. Reactions were stopped by incubating the Falcon tubes at $100{ }^{\circ} \mathrm{C}$ for $15 \mathrm{~min}$ in a water bath. Supernatants were collected by centrifugation of the tubes for $15 \mathrm{~min}$ at $3803 \mathrm{~g}$ and $4{ }^{\circ} \mathrm{C}$, and these were then transferred to $1.5-\mathrm{mL}$ tubes and stored at $-20{ }^{\circ} \mathrm{C}$ prior to further analysis.

\section{Product analysis}

Glucose and cellobiose released during enzymatic hydrolysis were quantified with High-Performance Liquid Chromatography (HPLC) using a Dionex Ultimate 3000 system (Dionex, Sunnyvale, CA, USA) coupled to a refractive index (RI) detector 101 (Shodex, Tokyo, Japan). Separation of hydrolysis products was achieved utilizing a Rezex ROA-Organic Acid $\mathrm{H}^{+}(8 \%), 300 \times 7.8 \mathrm{~mm}$ analytical column equipped with SecureGuard Carbo- $\mathrm{H}^{+}$ $4 \times 3.0 \mathrm{~mm}$ guard column (Phenomenex, Torrance, CA, USA), operated at $65{ }^{\circ} \mathrm{C}$, with $5 \mathrm{~mm} \mathrm{H}_{2} \mathrm{SO}_{4}$ as the mobile phase, and a flow rate of $0.6 \mathrm{~mL} / \mathrm{min}$. For quantification, the areas of peaks corresponding to glucose and cellobiose were compared to standard curves generated with known concentrations of glucose and cellobiose (in the range of $0.1-10 \mathrm{~g} / \mathrm{L}$ ). Hydrolysis yields were calculated based on detected glucose and cellobiose (typically less than $1 \%$ of the total) and expressed as a percentage of the theoretical maximum that would be obtained upon complete conversion of glucan to glucose.

Statistical significance of differences in glucan saccharification yields was determined using two-way ANOVA with Tukey's post hoc test (95\% confidence interval) and was carried out using R ( $\mathrm{R}$ Foundation for Statistical Computing, Vienna, Austria). Statistical significance is shown as follows: $p<0.05, * p<0.01,{ }^{* * * *} p<0.001$.

Native cello-oligosaccharides (DP 2 to DP 5) and oxidized sugars were analyzed with High-Performance Anion Exchange Chromatography with Pulsed Amperometric Detection (HPAEC-PAD) using a Dionex ICS 3000 system (Dionex, Sunnyvale, CA, USA) equipped with a CarboPac PA1 $2 \times 250 \mathrm{~mm}$ analytical column with a CarboPac PA1 $2 \times 50 \mathrm{~mm}$ guard column, as described in [15]. Briefly, initial conditions were set to $0.1 \mathrm{M} \mathrm{NaOH}$
(100\% eluent A), followed by a linear gradient of eluent B (1 M sodium acetate in $0.1 \mathrm{M} \mathrm{NaOH})$, reaching $10 \% \mathrm{~B}$ 10 min after sample injection and 30\% B at 35 min after injection. This was followed by a 5-min exponential gradient to $100 \%$ eluent $\mathrm{B}$, after which the column was reconditioned by running the initial conditions for $9 \mathrm{~min}$.

C4-oxidized standards were generated with NcLPMO9C by cellopentaose degradation as described in [24]. The data were collected and analyzed using Chromeleon 7.0 software.

\section{Results}

Below, several series of hydrolysis experiments are described. Table 2 provides an overview of the hydrolysis yields obtained in these experiments.

\section{Saccharification of a model cellulosic substrate}

The model cellulosic substrate Avicel PH-101 was incubated for $48 \mathrm{~h}$ with an older generation, LPMO-poor, cellulase mixture (Celluclast $^{\circledR}$ 1.5L supplemented with Novozym 188; 5:1, w/w), as well as a modern, LPMOcontaining, cellulase preparation, Cellic ${ }^{\circledR} \mathrm{CTec} 3$, under either aerobic or anaerobic conditions, in the presence or absence of an external electron donor (ascorbic acid). These experiments showed that Cellic ${ }^{\circledR}$ CTec3 gives higher hydrolysis yields, but only under aerobic conditions and when adding an external electron donor (Fig. 1a). Indeed, under these conditions only, considerable LPMO activity was detectable (Fig. 1b; the amount of C4-oxidized product amounts to approximately $1.5 \%$ of the amount of solubilized glucan). Saccharification of Avicel with the Celluclast ${ }^{\circledR}$ 1.5L:Novozym 188 mixture was hardly affected by the presence of oxygen or the addition of ascorbic acid (Fig. 1c), and under LPMO-promoting conditions, only low product levels were observed (Fig. 1d). Celluclast ${ }^{\circledR} 1.5 \mathrm{~L}$ is a product based on the $T$. reesei secretome, in which three AA9 family LPMOs have been identified, which however, are expressed at low levels $[13,32]$.

\section{Saccharification of sulfite-pulped softwoods}

Sulfite-pulped Norway spruce was incubated with both cellulase preparations for $48 \mathrm{~h}$, under conditions identical to those used for Avicel, with strikingly similar results (Fig. 2a-d). Again, Cellic ${ }^{\circledR}$ CTec3 was the most efficient and, again, only under aerobic conditions and when adding an external source of electrons (Fig. 2a). Saccharification of pretreated Norway spruce with the LPMO-poor cocktail was not improved by aerobic conditions or the presence of electron donor (Fig. 2c). Oxidized products were only observed for reactions with oxygen and externally added electron donor present, and the levels of oxidized product were much higher for Cellic ${ }^{\circledR} \mathrm{CTec} 3$ (Fig. 2b), compared 
Table 2 Overview of hydrolysis yields for various degradation reactions

\begin{tabular}{|c|c|c|c|c|c|}
\hline Raw material & Enzyme & Conditions & AscA & $\begin{array}{l}\text { Sulfite } \\
(12.5 \mathrm{mM})\end{array}$ & $\begin{array}{l}\text { Glucan solubilization after } \\
48 \mathrm{~h} \text { (\% of theoretical) }\end{array}$ \\
\hline \multirow[t]{8}{*}{ Avicel PH-101 } & Cellic ${ }^{\circledR}$ CTec3 & Aerobic & + & - & $69.0 \pm 1.9$ \\
\hline & & Aerobic & + & + & $31.6 \pm 0.4$ \\
\hline & & Anaerobic & + & - & $50.0 \pm 1.4$ \\
\hline & & Anaerobic & + & + & $44.1 \pm 1.2$ \\
\hline & Celluclast $^{\circledR}:$ Novozym 188 & Aerobic & + & - & $55.6 \pm 0.9$ \\
\hline & & Aerobic & + & + & $39.5 \pm 0.5$ \\
\hline & & Anaerobic & + & - & $57.1 \pm 0.7$ \\
\hline & & Anaerobic & + & + & $38.6 \pm 4.3$ \\
\hline \multirow[t]{8}{*}{ Norway spruce } & Cellic ${ }^{\circledR}$ CTec3 & Aerobic & + & - & $73.7 \pm 0.7$ \\
\hline & & Aerobic & + & + & $34.1 \pm 0.4$ \\
\hline & & Anaerobic & + & - & $50.6 \pm 3.8$ \\
\hline & & Anaerobic & + & + & $55.6 \pm 2.3$ \\
\hline & Celluclast $^{\circledR}:$ Novozym 188 & Aerobic & + & - & $64.9 \pm 2.1$ \\
\hline & & Aerobic & + & + & $38.7 \pm 1.5$ \\
\hline & & Anaerobic & + & - & $60.2 \pm 1.4$ \\
\hline & & Anaerobic & + & + & $50.3 \pm 2.6$ \\
\hline \multirow[t]{2}{*}{ Loblolly pine } & Cellic ${ }^{\circledR}$ CTec3 & Aerobic & + & - & $84.3 \pm 1.2$ \\
\hline & & Anaerobic & + & - & $60.3 \pm 0.7$ \\
\hline
\end{tabular}

to the Celluclast ${ }^{\circledR}$ reaction (Fig. 2d). This result shows that the heavily delignified sulfite-pretreated softwood biomass lacks the potential to activate LPMOs.

Saccharification of sulfite-pulped loblolly pine with Cellic ${ }^{\circledR} \mathrm{CTec} 3$ using the same conditions and varying the same parameters showed the same trends as observed for Norway spruce and Avicel. Interestingly, saccharification of pretreated loblolly pine was clearly more efficient than identically pretreated Norway spruce (compare Fig. 2e with a). The higher conversion of loblolly pine was achieved despite a seemingly lower LPMO activity (compare Fig. $2 f$ with b).

The importance of oxygen, which affects LPMO activity, was explored further using extended reaction times (up to $144 \mathrm{~h}$ ). The results showed that enzymatic hydrolysis of sulfite-pulped Norway spruce under anaerobic conditions never reached the yields obtained under conditions promoting LPMO activity, the final yields being about 65 and $85 \%$, respectively (Fig. 3 ).

Reduced glutathione and gallic acid can also drive LPMO activity by acting as electron donors [10, 15, 25]. Similarly to the addition of ascorbic acid, addition of each of these reducing agents improved enzymatic degradation of pretreated Norway spruce under aerobic conditions (Additional file 1: Figure S1a, b) albeit less efficiently than ascorbic acid (Fig. 2a).

Repeating the experiments with sulfite-pulped Norway spruce, in the absence of $\mathrm{L}$-cysteine hydrochloride monohydrate $(0.025 \%, \mathrm{w} / \mathrm{v})$, showed that the addition of this compound, used to ensure anaerobic conditions, had no effect on hydrolysis yields (Additional file 2: Figure S2).

\section{Effect of residual sulfite on softwood saccharification}

The sulfite-pretreated biomasses used in the experiments described above had been stored for some time and were likely devoid of residual sulfite, which is readily oxidized to sulfate in a reaction that involves oxygen and leads to the generation of various reactive intermediate species [33]. Sulfite pretreatment of lignocelluloses in a factory may result in residual sulfite still being present in the material that is subjected to subsequent enzymatic hydrolysis. To test how residual sulfite would affect enzymatic hydrolysis, we studied the effect of sulfite on hydrolysis of Avicel (Additional file 3: Figure S3) and pretreated Norway spruce (Fig. 4) by Cellic ${ }^{\circledR} \mathrm{CTec} 3$ and the Celluclast ${ }^{\circledR}$-based cocktail. We tested the effect of adding $1000 \mathrm{ppm}(12.5 \mathrm{mM})$ of sulfite ions (in the form of freshly added sodium sulfite), which was considered to be at the higher end of the concentrations that could be expected to be present in freshly pretreated and washed biomass, based on process data from the BALI ${ }^{\mathrm{TM}}$ pilot plant at Borregaard AS. Generally, sulfite had a negative effect on enzymatic hydrolysis of all substrates and no LPMO products could be detected (Fig. 4; see also Additional file 1: Figure S1, Additional file 2: Figure S2, Additional file 3: Figure S3). Maximal conversion with Cellic ${ }^{\circledR} \mathrm{CTec} 3$ (i.e., aerobic, with AscA, 48 h) was reduced from 69.0 and $73.7 \%$ to 31.6 and $34.1 \%$ for Avicel and Norway spruce, 

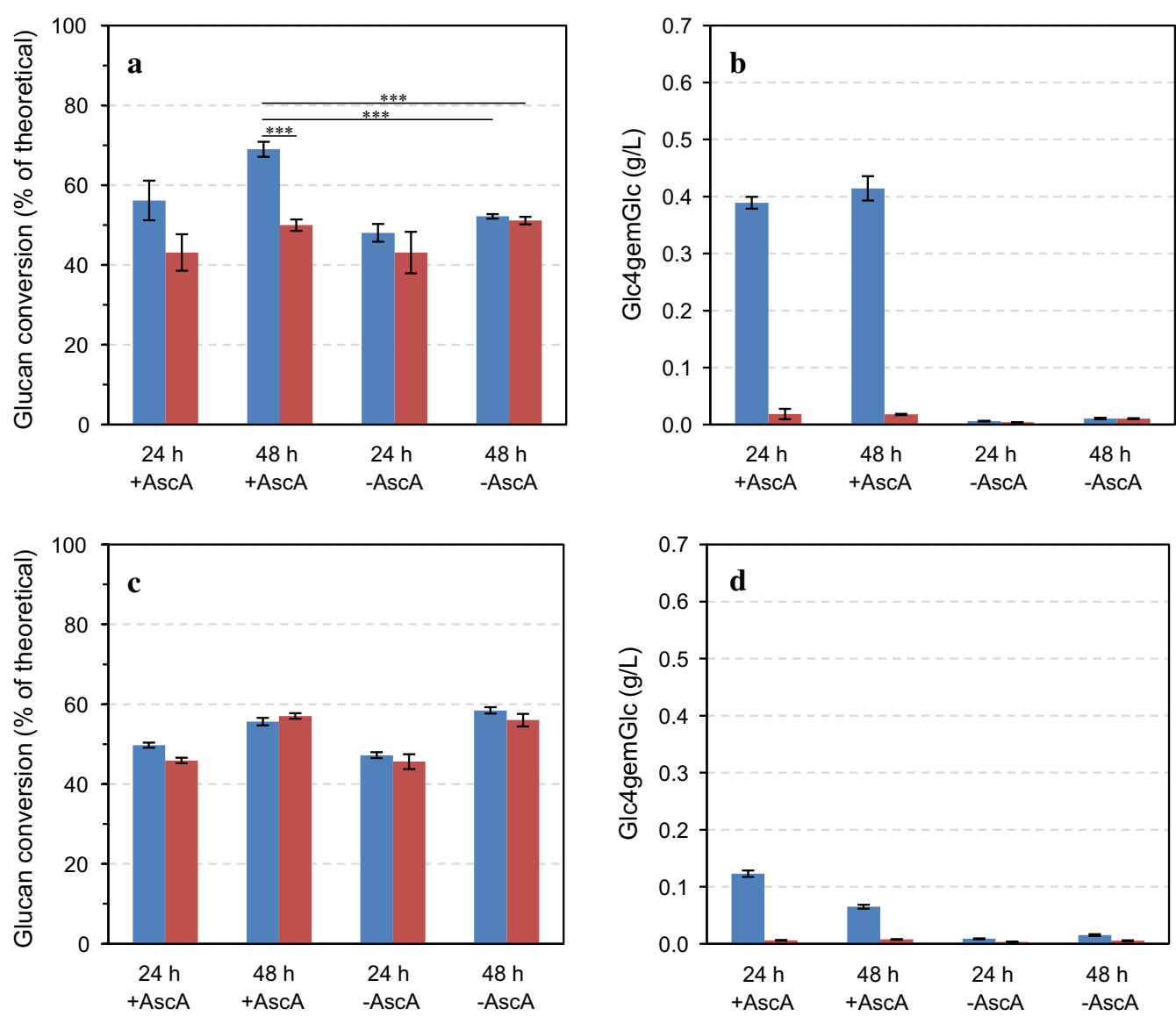

Fig. 1 Saccharification of Avicel PH-101 under aerobic (blue bars) or anaerobic (red bars) conditions in the presence or absence of $1 \mathrm{mM}$ ascorbic acid ( \pm AscA). The left panels show glucan conversion (as a percentage of theoretical glucan conversion) and the right panels show the concentration of Glc4gemGlc, at two time points. Enzymatic hydrolysis was carried out with Cellic ${ }^{\circledR}$ CTec3 (a, b) and Celluclast ${ }^{\circledR}:$ Novozym 188 (mixed at 5:1 ratio, w/w) (c, d) at $8 \mathrm{mg} / \mathrm{g}$ glucan total protein loading, using reaction mixtures containing 5\% DM in $50 \mathrm{mM}$ sodium acetate $\mathrm{pH} 5.0$ that were incubated at $50{ }^{\circ} \mathrm{C}$. The data points represent the average value of three independent experiments with one technical replicate per experiment. The error bars represent standard deviations of the three independent experiments. The statistical significance of differences in the 48-h saccharification yields was analyzed using two-way ANOVA with Tukey's post hoc test (95\% confidence interval) and is indicated as follows: ${ }^{*} p<0.05,{ }^{* *} p<0.01$, ${ }^{* * *} p<0.001$

respectively (Table 2). These decreases in yields are larger than the effects of oxygen and ascorbic acid discussed above and are thus not likely to be only "LPMO effects." Indeed, the efficiency of the LPMO-poor Celluclast ${ }^{\circledR}$ mixture was also affected by sulfite, albeit to a lesser extent (Table 2; Fig. 4; Additional file 3: Figure S3). The effect of sulfite was clearly less pronounced under anaerobic conditions, which could be due to the absence of reactions between oxygen and sulfite that may lead to the formation of various compounds, including the sulfite radical and other radicals [33] that inhibit the enzymes. In line with this, the addition of reducing agent (or "antioxidant") to the aerobic reactions had a clear positive effect on yields, despite the absence of LPMO activity (e.g., Figure 4). In the absence of reducing agent and in the presence of sulfite, hydrolysis yields were generally very low.

\section{Effect of lignosulfonates on degradation of sulfite-pretreated softwoods}

Besides a cellulose-rich pulp, sulfite pretreatment also yields lignosulfonates (LS), representing a valuable commodity from the lignin fraction of softwood biomass. It has been shown that LS can improve enzymatic saccharification of pretreated lignocellulosic materials [34, 35]. Using enzymatic hydrolysis of sulfite-pulped Norway spruce as a test case, we assessed whether LS could replace ascorbic acid. It can be observed from Fig. 5 that $0.25 \%(\mathrm{w} / \mathrm{w})$ LS led to increased hydrolysis yields under aerobic conditions, but to a smaller extent than the addition of ascorbic acid (Fig. 2). The increase in yield obtained by adding LS was accompanied by the production of oxidized products (Fig. 5b), albeit, again, at lower levels compared to reactions with ascorbic acid (Fig. 2b). 

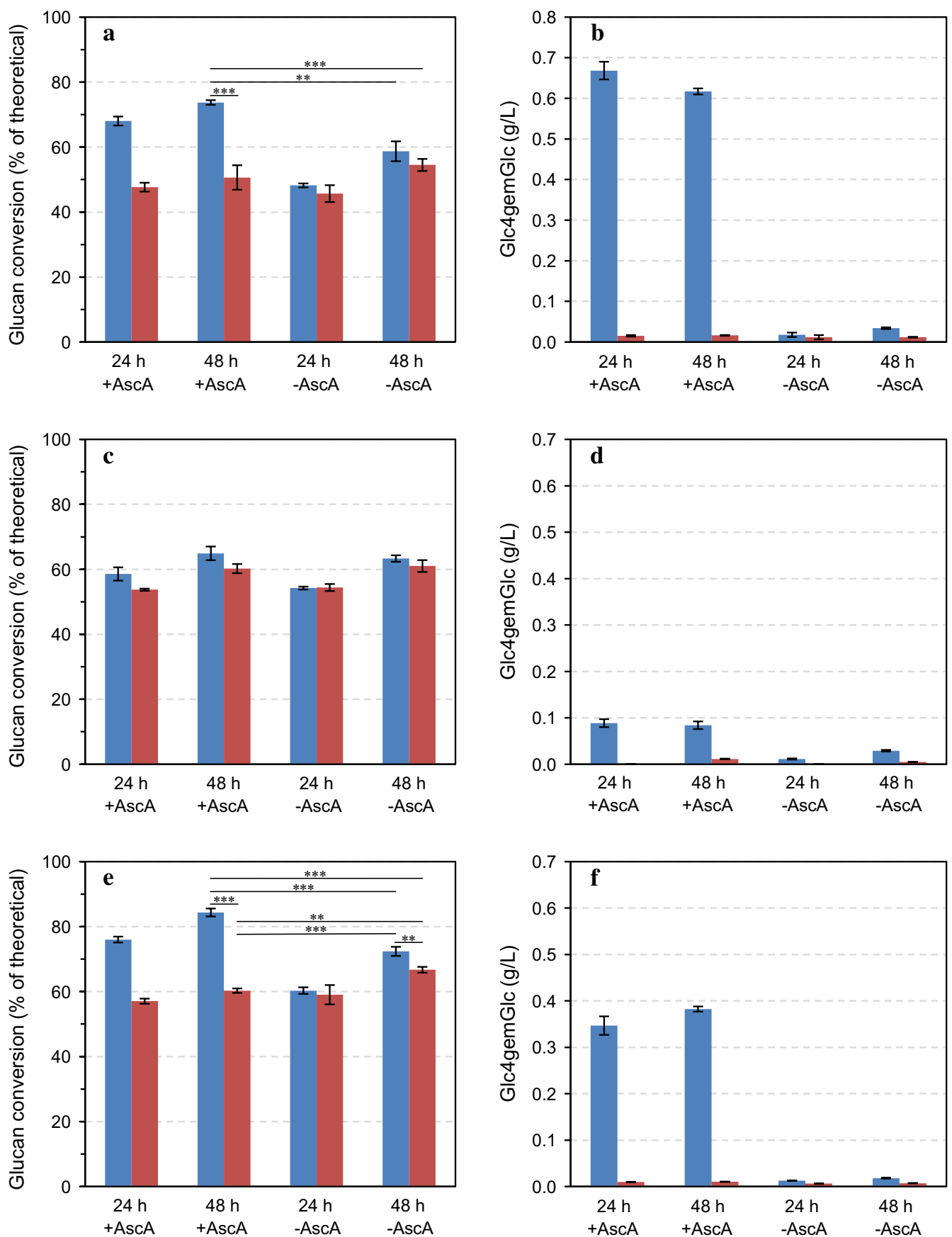

Fig. 2 Saccharification of pretreated Norway spruce (a-d) and loblolly pine (e-f) under aerobic (blue bars) or anaerobic (red bars) conditions in the presence or absence of $1 \mathrm{mM}$ ascorbic acid ( \pm AscA). The left panels show glucan conversion (as a percentage of theoretical glucan conversion) and the right panels show the concentration of Glc4gemGlc, at two time points. Enzymatic hydrolysis was carried out with Cellic ${ }^{\circledR} \mathrm{CTec} 3(\mathbf{a}, \mathbf{b}, \mathbf{e}, \mathbf{f})$ and Celluclast ${ }^{\circledR}$ :Novozym 188 (mixed at 5:1 ratio, w/w) (c, d) at 8 mg/g glucan total protein loading using reaction mixtures containing $5 \%$ DM in 50 mM sodium acetate $\mathrm{pH} 5.0$ that were incubated at $50^{\circ} \mathrm{C}$. The data points represent the average value of three independent experiments with one technical replicate per experiment. The error bars represent standard deviations of the three independent experiments. The statistical significance of differences in the 48-h saccharification yields was analyzed using two-way ANOVA with Tukey's post hoc test (95\% confidence interval) and is indicated as follows: ${ }^{*} p<0.05,{ }^{* *} p<0.01,{ }^{* * *} p<0.001$ 


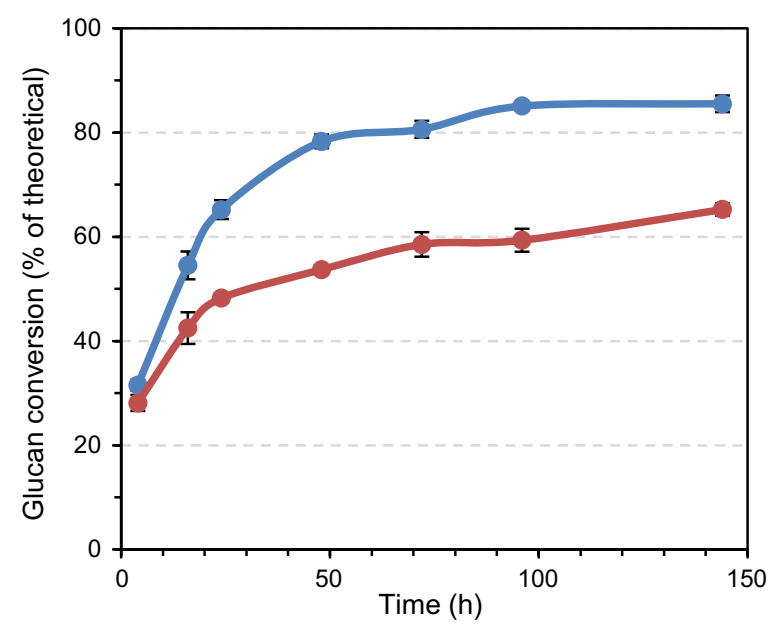

Fig. 3 Saccharification of pretreated Norway spruce under aerobic (blue line) or anaerobic (red line) conditions in the presence of $1 \mathrm{mM}$ ascorbic acid. Enzymatic hydrolysis was carried out with Cellic ${ }^{\circledR} \mathrm{CTec} 3$ at $8 \mathrm{mg} / \mathrm{g}$ glucan total protein loading in reaction mixtures containing 5\% DM in $50 \mathrm{mM}$ sodium acetate $\mathrm{pH} 5.0$ that were incubated at $50^{\circ} \mathrm{C}$. The data points represent the average value of three independent experiments with one technical replicate per experiment. The error bars represent standard deviations of the three independent experiments

Addition of LS helped also to mitigate the negative effect of sulfite ions on hydrolysis efficiency (Fig. 5c), but to a lower extent than ascorbic acid (Fig. 4a) and other tested reducing agents (Additional file 1: Figure S1c, d).

\section{Contribution of individual enzymes to saccharification efficiency}

Previous work on the development of minimal enzyme cocktails for conversion of $\mathrm{BALI}^{\mathrm{TM}}$-pretreated spruce has shown that of the best known individual $T$. reese $i$ cellulases, $\operatorname{TrCel7B}$ is the most important [36]. This study also indicated that a cellulose-active, bacterial LPMO (ScLPMO10C) had little effect on overall saccharification efficiency. Considering these previous results and the clear positive effect of LPMOs contained in Cellic ${ }^{\circledR}$ CTec3 on the saccharification of sulfite-pulped softwoods, we tested the potential of TaLPMO9A and three major $T$. reesei cellulases $(\operatorname{TrCel7A}, \operatorname{Tr} C \mathrm{Cl} 7 \mathrm{~B}$, and $\operatorname{TrCel6A})$ to improve the efficiency of the Celluclast ${ }^{\circledR} 1.5 \mathrm{~L}$ :Novozym 188 mix. We replaced $15 \%$ of the enzyme mixture by one of these individual enzymes because previous studies on spiking Celluclast ${ }^{\circledR}$ with TaLPMO9A had indicated that this level of replacement was optimal in terms of increased saccharification yield [24]. Replacement of $15 \%$ of total protein by individual cellulases revealed that the addition of TrCel7B was more beneficial than that of the other individual cellulases and led to a yield comparable with that obtained with $100 \%$ of the original cellulase preparation. In line with other results reported in this study, replacement of $15 \%$ of the cellulase preparation with TaLPMO9A had a clear beneficial effect on glucan conversion, but only when also ascorbic acid was added (Fig. 6).

\section{Discussion}

Since the discovery of the true nature of LPMOs [10], their role in the degradation of cellulose and pretreated lignocellulosic biomasses has been the subject of several studies [13, 23-25, 37]. For example, it has been shown that harnessing LPMO activity improves the saccharification of hydrothermally pretreated wheat straw [23] and steam-exploded birch [24] with an LPMO-rich cellulase preparation, Cellic ${ }^{\circledR} \mathrm{CTec} 2$. Both these studies also showed that LPMO activity does not require the presence of externally added small molecule reducing agents, as long as the substrate is rich in lignin. A similar conclusion was drawn by $\mathrm{Hu}$ et al. [25] in their study focused on spiking cellulase preparations with an AA9 LPMO in the degradation of several pretreated lignocelluloses. Importantly, the study by Müller et al. (2015) established the importance of the presence of oxygen in harnessing the full potential of LPMOs.

From previous work, it is known that sulfite-pretreated softwoods can be degraded quite efficiently with commercially available cellulase preparations [5, 38]. Sulfite pulping using the $\mathrm{BALI}^{\mathrm{TM}}$ pretreatment yields cellulose-rich and almost lignin-free materials that are also relatively easy to degrade [6]. So far, the potential role of LPMOs in the degradation of sulfite-pretreated biomasses has not been addressed, nor have the implications of a possible role of LPMOs on process design. The present experiments, using both a model cellulosic substrate and industrially relevant, sulfite-pulped softwoods, shed light on these issues. The data show a clear correlation between the efficiency of saccharification and the detection of LPMO-generated products, underpinning the major contribution of LPMOs to the saccharification process, which amounts to increases in saccharification yield by up to $24 \%$ (in the case of sulfitepulped loblolly pine). The presence of an externally added electron donor and aerobic conditions during enzymatic hydrolysis are both crucial for LPMO activity and for fully exploiting the cellulolytic potential of modern cellulase preparations. The requirement for an external electron donor to harness LPMO activity separates sulfite-pulped lignocelluloses from biomasses subjected to other physicochemical pretreatments and is likely due to extensive lignin removal during sulfite pulping (Table 1). The small amount of remaining lignin bound to the cellulose is most likely sulfonated, which will alter 

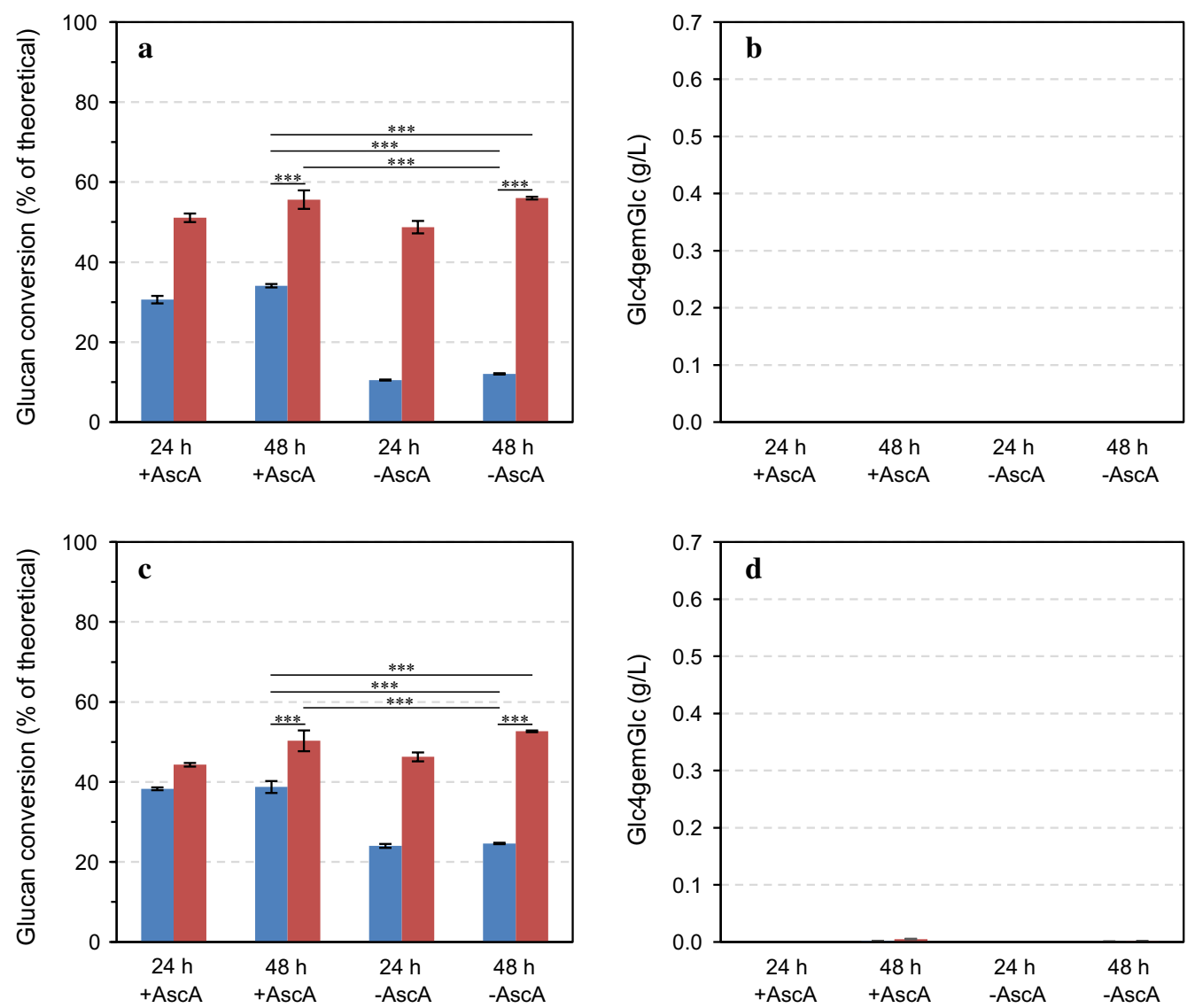

Fig. 4 Saccharification of pretreated Norway spruce in the presence of sulfite under aerobic (blue bars) or anaerobic (red bars) conditions, in the presence or absence of $1 \mathrm{mM}$ ascorbic acid ( \pm AscA). The left panels show glucan conversion (as a percentage of theoretical glucan conversion) and the right panels show concentrations of Glc4gem Glc, at two time points. Enzymatic hydrolysis was carried out with Cellic ${ }^{\circledR} \mathrm{CTec} 3(\mathbf{a}, \mathbf{b})$ and Celluclast ${ }^{\circledR}:$ Novozym 188 (mixed at 5:1 ratio, w/w) (c) d) at $8 \mathrm{mg} / \mathrm{g}$ glucan total protein loading in reactions containing 5\% DM in $50 \mathrm{mM}$ sodium acetate $\mathrm{pH} 5.0$ that were incubated at $50^{\circ} \mathrm{C}$. Data for similar reactions without sulfite are presented in Fig. 2 and data for the effect of sulfite on hydrolysis of Avicel are presented in Additional file 3: Figure S3. The data points represent the average value of three independent experiments with one technical replicate per experiment. The error bars represent standard deviations of the three independent experiments. The statistical significance of differences in the 48-h saccharification yields was analyzed using two-way ANOVA with Tukey's post hoc test (95\% confidence interval) and is indicated as follows: ${ }^{*} p<0.05,{ }^{* *} p<0.01,{ }^{* *} p<0.001$

its properties, e.g., the degree of hydrophilicity, relative to, e.g., the lignin present in steam-exploded materials [3]. Dimarogona et al. [39] and Westereng et al. [40] have demonstrated that lignin is capable of transferring electrons to LPMOs and stimulate their activity in cellulose decomposition, whereas $\mathrm{Hu}$ et al. [25] have shown that complete lignin removal from steam-pretreated lodgepole pine nearly completely eliminated the boosting effect of adding an LPMO. Finally, by studying enzymatic saccharification of sugarcane bagasse samples obtained from different pretreatments and with varying degrees of delignification, Rodríguez-Zúñiga et al. [41] showed a positive correlation between lignin content and LPMO activity. All these results confirm early observations by Harris et al. [13], who showed that the enigmatic boosting effect of a GH61 protein (which later turned out to be an LPMO) on cellulase activity depended on the presence of lignin.

In the presence of ascorbate and under aerobic conditions, improvement of the enzymatic degradation of sulfite-pretreated softwoods was correlated with the accumulation of oxidized products. The positive effect of LPMO-promoting conditions was only observed when using LPMO-rich cellulase preparation Cellic ${ }^{\circledR}$ CTec3 and when spiking an older cellulase preparation, LPMOpoor Celluclast ${ }^{\circledR} 1.5 \mathrm{~L}$, with TaLPMO9A. The dependence on oxygen is evident from both the present study and earlier work on steam-exploded birch by Müller et al. [24]. Interestingly, there are recent indications that LPMO reactions may be driven by $\mathrm{H}_{2} \mathrm{O}_{2}$ instead of $\mathrm{O}_{2}$ 

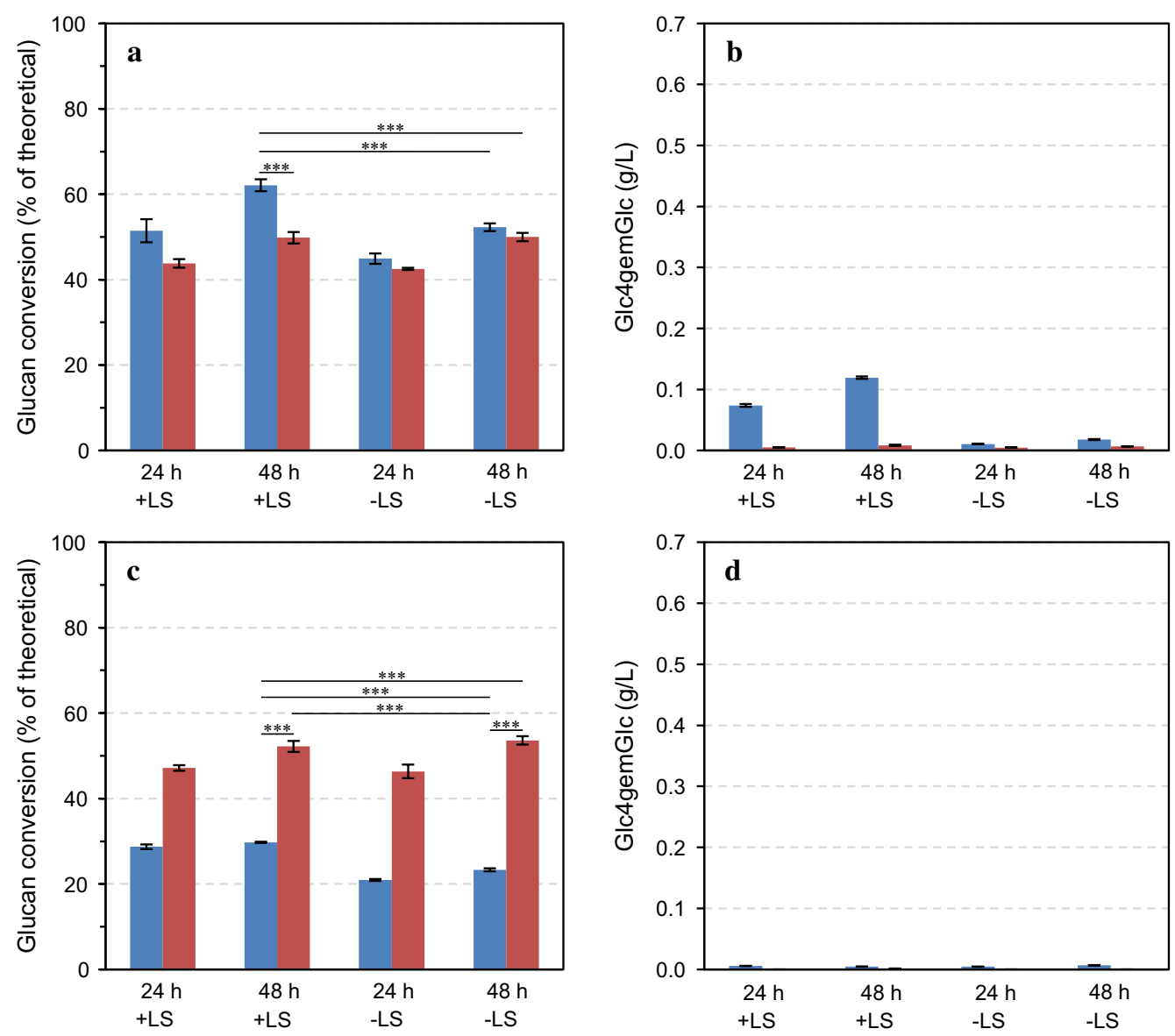

Fig. 5 Saccharification of pretreated Norway spruce in the absence $(\mathbf{a}, \mathbf{b})$ or presence $(\mathbf{c}, \mathbf{d})$ of sulfite under aerobic (blue bars) or anaerobic (red bars) conditions, in the presence or absence of $0.25 \%(\mathrm{w} / \mathrm{w}$ ) lignosulfonates (LS). The left panels show glucan conversion (as a percentage of theoretical glucan conversion) and the right panels show concentrations of Glc4gemGlc, at two time points. Enzymatic hydrolysis was carried out with Cellic ${ }^{\circledR} \mathrm{CTec} 3$ at $8 \mathrm{mg} / \mathrm{g}$ glucan total protein loading in reactions containing $5 \% \mathrm{DM}$ in $50 \mathrm{mM}$ sodium acetate $\mathrm{pH} 5.0$ that were incubated at $50{ }^{\circ} \mathrm{C}$. The data points represent the average value of three independent experiments with one technical replicate per experiment. The error bars represent standard deviations of the three independent experiments. The statistical significance of differences in the 48 -h saccharification yields was analyzed using two-way ANOVA with Tukey's post hoc test (95\% confidence interval) and is indicated as follows: ${ }^{*} p<0.05,{ }^{* *} p<0.01,{ }^{* * *} p<0.001$

and that in such a set-up the LPMO requires only substoichiometric amounts of reductant [9]. While further work is needed to study the implications of this novel way to drive LPMO activity, it is worth noting that the use of $\mathrm{H}_{2} \mathrm{O}_{2}$ may change or even abolish the need for supplying molecular oxygen and reductant in industrial biorefining. Supplying and controlling hydrogen peroxide, which is soluble in water, in high dry matter hydrolysis reactors may be easier, compared to using oxygen.

Careful inspection of Figs. 1 (hydrolysis of Avicel) and 2 (hydrolysis of sulfite-pulped Norway spruce) shows that under conditions that do not lead to LPMO activity, the Celluclast ${ }^{\circledR}$ :Novozym 188 cocktail is more efficient than Cellic ${ }^{\circledR}$ CTec3. Under these conditions, the LPMO fraction of the Cellic ${ }^{\circledR}$ CTec3 enzyme cocktail, perhaps amounting to $15 \%$ of the protein, is not active, meaning a reduced effective enzyme load. This observation underpins the importance of harnessing the power of LPMOs in modern cellulase cocktails.

While sulfite pulping generally seems to be a good pretreatment for softwoods, the present data show that residual sulfite that might be carried over from the pretreatment step to the enzymatic hydrolysis step has a negative effect on saccharification efficiency. The oxidation of sulfite to sulfate happens via a multi-step pathway involving the formation of several reactive intermediates [33] that are known to interact with, e.g., proteins $[33,42,43]$. For example, radicals formed during oxidation of sulfite react with methionine and tryptophan in proteins, which could easily lead to enzyme inactivation [33, 43]. Reducing agents, such as ascorbic acid, are commonly used in the food industry to protect from 


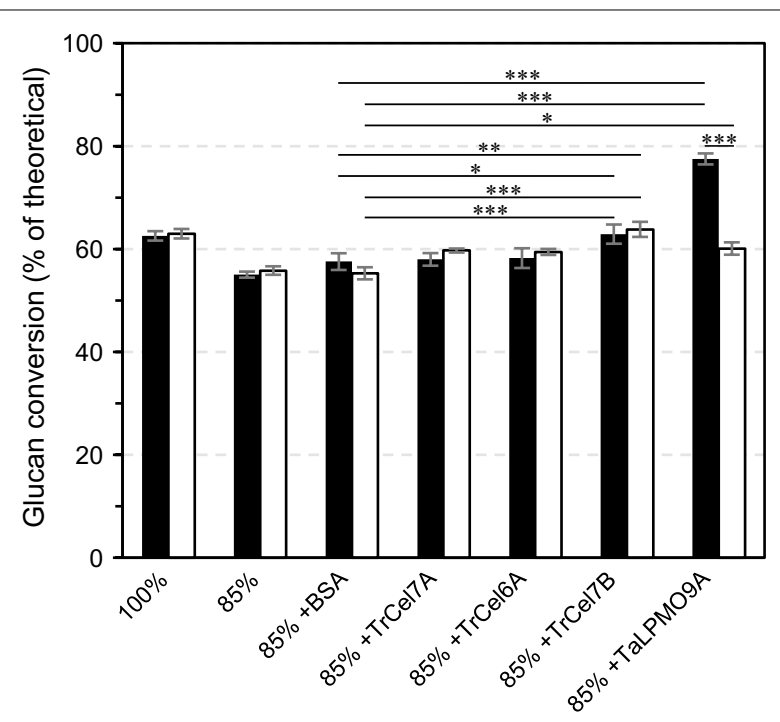

Fig. 6 Saccharification of pretreated Norway spruce in the presence (black bars) or absence (white bars) of $1 \mathrm{mM}$ ascorbic acid. Enzymatic hydrolysis was carried out with the Celluclast ${ }^{\circledR}$ :Novozym 188 mix (5: 1 W/W) supplemented with major Trichoderma reesei cellulases (TrCel7A, TrCel6A, and TrCel7B) or TaLPMO9A. The total protein loading was $8 \mathrm{mg} / \mathrm{g}$ glucan, except for the sample labeled " $85 \%$," where the total protein loading was at $6.8 \mathrm{mg} / \mathrm{g}$ glucan. The indicated individual enzymes comprised $15 \%$ of the total protein loading; BSA was used as a control. Experiments were carried out in reactions containing $5 \% \mathrm{DM}$ in $50 \mathrm{mM}$ sodium acetate $\mathrm{pH} 5.0$ at $50^{\circ} \mathrm{C}$ and were incubated at $50^{\circ} \mathrm{C}$ for $48 \mathrm{~h}$. The data points represent the average value of three independent experiments with one technical replicate per experiment. The error bars represent standard deviations of the three independent experiments. The statistical significance of differences in glucan conversion between the control reactions with BSA and reactions with added individual enzymes (in the presence or absence of $1 \mathrm{mM}$ ascorbic acid) was analyzed using two-way ANOVA with Tukey's post hoc test ( $95 \%$ confidence interval) and is indicated as follows: ${ }^{*} p<0.05,{ }^{* *} p<0.01,{ }^{* * *} p<0.001$

oxidative damage caused by reactive oxygen species, and indeed our results show that reducing agents prevent the enzyme inactivation happening under aerobic conditions in the presence of sulfite. The lack of LPMO products under these conditions shows that the positive effect of reductants is rather due to the scavenging of free radicals formed during oxidation of sulfite than to the promotion of LPMO activity. Obviously, utilization of large amounts of costly chemicals such as reductants is not economically feasible. Thus, the development of enzymes resistant to high sulfite concentrations or introduction of process steps for removing residual sulfite should be considered. Notably, further research on actual sulfite levels within the biorefinery is needed and so are studies on sulfite stability. The conditions used in this study, where we used high amounts of freshly added sodium sulfite, are not representative of the conditions in a real biorefinery.
It was known from before that lignosulfonates may have a positive effect on the saccharification of sulfite-pretreated lignocellulosic biomasses [34, 35]. These positive effects have been ascribed to the surfactant properties of LS [34] or to the formation of lignosulfonate-cellulase complexes [35], where both effects were thought to lead to reduced non-productive binding of cellulases to the substrate. In the present study, we observed that the positive effect of LS on hydrolysis efficiency was only present under aerobic conditions (Fig. 5a) and was linked to the promotion of LPMO activity (Fig. 5b). Interestingly, we also observed that LS reduced the negative effect of sulfite ions, though to a lesser extent than ascorbate. The exact mechanism of the stimulation of LPMO activity by LS addition is unknown and warrants further research. Notably, this effect could involve the interplay between (soluble) LS and residual lignin bound to the cellulose, which would be analogous to the interplay between solid and soluble lignin described by Westereng et al. [40].

\section{Conclusions}

In this study, we have demonstrated efficient enzymatic conversion of sulfite-pretreated softwoods by Cellic ${ }^{\circledR}$ $\mathrm{CTec} 3$ and we have demonstrated the importance of LPMOs in this process. We have also shown that, in order to obtain the high saccharification yields that are possible due to LPMO action, it is crucial that process conditions are adapted to the LPMOs, which need oxygen and reducing equivalents. The removal of residual sulfite from pretreatments is of major importance and both assessment of typical sulfite levels and methods to deal with these need further attention. Lignosulfonates have a potential to act as the electron donor for LPMOs, which could reduce the costs related to the addition of small molecule reductants in sulfite pretreatment-based biorefineries.

\section{Additional files}

Additional file 1: Figure $\mathbf{S 1}$. Saccharification of pretreated Norway spruce in the absence $(\mathbf{a}, \mathbf{b})$ or presence $(\mathbf{c}, \mathbf{d})$ of sulfite under aerobic (blue bars) or anaerobic (red bars) conditions in the presence or absence of $1 \mathrm{mM}$ gallic acid (+/- GA; left panels) or reduced glutathione (+/- RG; right panels). Enzymatic hydrolysis was carried out with Cellic ${ }^{\circledR}$ CTec3 at 8 $\mathrm{mg} / \mathrm{g}$ glucan total protein loading in reaction mixtures containing 5\% DM that were incubated in $50 \mathrm{mM}$ sodium acetate $\mathrm{pH} 5.0$, at $50^{\circ} \mathrm{C}$. Reactions with sulfite (lower pane/s) contained $1000 \mathrm{ppm}$ of sulfite ions added as a sodium sulfite $(12.5 \mathrm{mM})$. The data points represent the average value of three independent experiments with one technical replicate per experiment. The error bars represent standard deviations of the three independent experiments. The statistical significance of differences in the 48 hour saccharification yields was analyzed using two-way ANOVA with Tukey's post hoc test ( $95 \%$ confidence interval), and is indicated as follows: *, $p<0.05 ;{ }^{* *}, p<0.01 ;{ }^{* * *}, p<0.001$. 
Additional file 2: Figure S2. Saccharification of sulfite-pretreated Norway spruce without addition of L-cysteine hydrochloride monohydrate $(0.025 \% \mathrm{w} / \mathrm{v})$ in the anaerobic reactions, in the absence $(\mathbf{a}, \mathbf{b})$ or presence (c, d) of sulfite under aerobic (blue bars) or anaerobic (red bars) conditions, in the presence or absence of $1 \mathrm{mM}$ ascorbic acid (+/-AscA). The left panels show glucan conversion (as a percentage of theoretical glucan conversion) and the right panels show the concentration of Glc4gemGlc, at two time points. Enzymatic hydrolysis was carried out with $\mathrm{Cellic}^{\circledR}$ CTec3 at $8 \mathrm{mg} / \mathrm{g}$ glucan total protein loading in reaction mixtures containing 5\% DM in $50 \mathrm{mM}$ sodium acetate $\mathrm{pH} 5.0$ that were incubated at $50^{\circ} \mathrm{C}$. Reactions with sulfite (lower pane/s) contained $1000 \mathrm{ppm}$ of sulfite ions added as a sodium sulfite $(12.5 \mathrm{mM})$. The data points represent the average value of three independent experiments with one technical replicate per experiment. The error bars represent standard deviations of the three independent experiments. The statistical significance of differences in the 48 hour saccharification yields was analyzed using two-way ANOVA with Tukey's post hoc test ( $95 \%$ confidence interval), and is indicated as follows: ${ }^{*}, p<0.05 ;{ }^{* *}, p<0.01 ;{ }^{* * *}, p<0.001$

Additional file 3: Figure S3. Saccharification of Avicel PH-101 in the presence of sulfite under aerobic (blue bars) or anaerobic (red bars) conditions, in the presence or absence of $1 \mathrm{mM}$ ascorbic acid (+/-AscA). The left panels show glucan conversion (as a percentage of theoretical glucan conversion) and the right panels show concentration of Glc4gemGlc, at two time points. Enzymatic hydrolysis was carried out with Cellic ${ }^{\circledR} \mathrm{CTec} 3$ (a, b) and Celluclast:Novozym 188 (mixed at 5:1 ratio, w/w) (c, d) at 8 $\mathbf{m g} / \mathrm{g}$ glucan total protein loading in reaction mixtures containing $5 \%$ $\mathrm{DM}$ in $50 \mathrm{mM}$ sodium acetate $\mathrm{pH} 5.0$ that were incubated at $50^{\circ} \mathrm{C}$. Data for similar reactions without sulfite are presented in Fig. 1. The data points represent the average value of three independent experiments with one technical replicate per experiment. The error bars represent standard deviations of the three independent experiments. The statistical significance of differences in the 48 hour saccharification yields was analyzed using two-way ANOVA with Tukey's post hoc test ( $95 \%$ confidence interval), and is indicated as follows: ${ }^{*}, p<0.05 ;{ }^{* *}, p<0.01 ;{ }^{* * *}, p<0.001$.

\section{Abbreviations}

AA: auxiliary activity; AscA: ascorbic acid; Glc4gemGlc: 4-hydroxy-ß-D-xylohexopyranosyl-( $1 \rightarrow 4)-\beta$-D-glucopyranosyl; HPAEC: high-performance anion exchange chromatography; HPLC: high-performance liquid chromatography; LPMO: Iytic polysaccharide monooxygenase; LS: lignosulfonates.

\section{Authors' contributions}

$\mathrm{PC}, \mathrm{MD}, \mathrm{OB}, \mathrm{ML}, \mathrm{SJH}$, and VGHE designed the experiments and interpreted the results; SJH and VGHE supervised the study; PC did most of the experimental work; DP, GM, and MS-A contributed with experiments, materials, and ideas. PC drafted the manuscript, with help from GM, SJH, and VGHE; PC and VGHE finalized the manuscript. All authors read and approved the final manuscript.

\section{Author details}

1 Faculty of Chemistry, Biotechnology and Food Science, Norwegian University of Life Sciences, P.O. Box 5003, 1432 Ås, Norway. ${ }^{2}$ Borregaard AS, P.O.Box 162, 1701 Sarpsborg, Norway. ${ }^{3}$ VTT Technical Research Centre of Finland, P.O. Box 1000, 02044 VTT Espoo, Finland.

\section{Acknowledgements}

The authors would like to acknowledge Kristin Hals (Borregaard AS, Sarpsborg, Norway) for performing compositional analysis of industrial lignocellulosic substrates.

\section{Competing interests}

Lersch and Bengtsson are employees of Borregaard AS, Sarpsborg, Norway. Marie Dahlström was at the time of completing this work an employee of Borregaard AS, Sarpsborg, Norway.

\section{Availability of supporting data}

Supporting data are provided in Additional files 1, 2, and 3.
Funding

This work was funded by the Research Council of Norway, through Grant 219633.

\section{Publisher's Note}

Springer Nature remains neutral with regard to jurisdictional claims in published maps and institutional affiliations.

Received: 7 March 2017 Accepted: 28 June 2017

Published online: 11 July 2017

References

1. Zhu JY, Pan XJ. Woody biomass pretreatment for cellulosic ethanol production: technology and energy consumption evaluation. Bioresour Technol. 2010;101(13):4992-5002. doi:10.1016/j.biortech.2009.11.007.

2. Himmel ME, Ding SY, Johnson DK, Adney WS, Nimlos MR, Brady JW, et al. Biomass recalcitrance: engineering plants and enzymes for biofuels production. Science. 2007;315(5813):804-7. doi:10.1126/science.1137016.

3. Leu SY, Zhu JY. Substrate-related factors affecting enzymatic saccharification of lignocelluloses: our recent understanding. Bioenergy Res. 2013;6(2):405-15. doi:10.1007/s12155-012-9276-1.

4. Pan XJ, Arato C, Gilkes N, Gregg D, Mabee W, Pye K, et al. Biorefining of softwoods using ethanol organosolv pulping: preliminary evaluation of process streams for manufacture of fuel-grade ethanol and co-products. Biotechnol Bioeng. 2005;90(4):473-81. doi:10.1002/bit.20453.

5. Zhu JY, Pan XJ, Wang GS, Gleisner R. Sulfite pretreatment (SPORL) for robust enzymatic saccharification of spruce and red pine. Bioresour Technol. 2009;100(8):2411-8. doi:10.1016/j.biortech.2008.10.057.

6. Rødsrud G, Lersch M, Sjöde A. History and future of world's most advanced biorefinery in operation. Biomass Bioenergy. 2012;46:46-59. doi:10.1016/j.biombioe.2012.03.028.

7. Merino ST, Cherry J. Progress and challenges in enzyme development for biomass utilization. Adv Biochem Eng Biotechnol. 2007;108:95-120. doi:10.1007/10_2007_066.

8. Jørgensen $\mathrm{H}$, Kristensen JB, Felby C. Enzymatic conversion of lignocellulose into fermentable sugars: challenges and opportunities. Biofuel Bioprod Biorefin. 2007;1(2):119-34. doi:10.1002/bbb.4.

9. Bissaro B, Røhr AK, Skaugen M, Forsberg Z, Horn SJ, Vaaje-Kolstad G, et al. Fenton-type chemistry by a copper enzyme: molecular mechanism of polysaccharide oxidative cleavage. cleavage. 2017. doi:10.1101/097022.

10. Vaaje-Kolstad G, Westereng B, Horn SJ, Liu ZL, Zhai H, Sorlie M, et al. An oxidative enzyme boosting the enzymatic conversion of recalcitrant polysaccharides. Science. 2010;330(6001):219-22. doi:10.1126/ science.1192231.

11. Quinlan RJ, Sweeney MD, Lo Leggio L, Otten H, Poulsen JC, Johansen $\mathrm{KS}$, et al. Insights into the oxidative degradation of cellulose by a copper metalloenzyme that exploits biomass components. Proc Natl Acad Sci USA. 2011;108(37):15079-84. doi:10.1073/pnas.1105776108.

12. Hemsworth GR, Henrissat B, Davies GJ, Walton PH. Discovery and characterization of a new family of lytic polysaccharide monooxygenases. Nat Chem Biol. 2014;10(2):122-6. doi:10.1038/nchembio.1417.

13. Harris PV, Welner D, McFarland KC, Re E, Navarro Poulsen JC, Brown K, et al. Stimulation of lignocellulosic biomass hydrolysis by proteins of glycoside hydrolase family 61: structure and function of a large, enigmatic family. Biochemistry. 2010;49(15):3305-16. doi:10.1021/bi100009p.

14. Phillips CM, Beeson WT, Cate JH, Marletta MA. Cellobiose dehydrogenase and a copper-dependent polysaccharide monooxygenase potentiate cellulose degradation by Neurospora crassa. ACS Chem Biol. 2011;6(12):1399-406. doi:10.1021/cb200351y.

15. Forsberg Z, Vaaje-Kolstad G, Westereng B, Bunæs AC, Stenstrøm Y, MacKenzie A, et al. Cleavage of cellulose by a CBM33 protein. Protein Sci. 2011;20(9):1479-83. doi:10.1002/pro.689.

16. Westereng B, Ishida T, Vaaje-Kolstad G, Wu M, Eijsink VGH, Igarashi K, et al. The putative endoglucanase PCGH61D from Phanerochaete chrysosporium is a metal-dependent oxidative enzyme that cleaves cellulose. PLoS ONE. 2011;6(11):e27807. doi:10.1371/journal.pone.0027807. 
17. Isaksen T, Westereng B, Aachmann FL, Agger JW, Kracher D, Kittl R, et al. A C4-oxidizing lytic polysaccharide monooxygenase cleaving both cellulose and cello-oligosaccharides. J Biol Chem. 2014;289(5):2632-42. doi:10.1074/jbc.M113.530196.

18. Agger JW, Isaksen T, Várnai A, Vidal-Melgosa S, Willats WGT, Ludwig R, et al. Discovery of LPMO activity on hemicelluloses shows the importance of oxidative processes in plant cell wall degradation. Proc Natl Acad Sci USA. 2014;111(17):6287-92. doi:10.1073/pnas.1323629111.

19. Frommhagen $M$, Sforza S, Westphal AH, Visser J, Hinz SWA, Koetsier MJ, et al. Discovery of the combined oxidative cleavage of plant xylan and cellulose by a new fungal polysaccharide monooxygenase. Biotechnol Biofuels. 2015;8:101. doi:10.1186/s13068-015-0284-1.

20. Vu W, Beeson WT, Span EA, Farquhar ER, Marletta MA. A family of starch-active polysaccharide monooxygenases. Proc Natl Acad Sci USA. 2014;111(38):13822-7. doi:10.1073/pnas.1408090111.

21. Lo Leggio L, Simmons TJ, Poulsen JC, Frandsen KE, Hemsworth GR, Stringer MA, et al. Structure and boosting activity of a starch-degrading lytic polysaccharide monooxygenase. Nat Commun. 2015;6:5961. doi:10.1038/ncomms6961.

22. Levasseur A, Drula E, Lombard V, Coutinho PM, Henrissat B. Expansion of the enzymatic repertoire of the CAZy database to integrate auxiliary redox enzymes. Biotechnol Biofuels. 2013;6:41. doi:10.1186/1754-6834-6-41.

23. Cannella D, Hsieh CWC, Felby C, Jørgensen $H$. Production and effect of aldonic acids during enzymatic hydrolysis of lignocellulose at high dry matter content. Biotechnol Biofuels. 2012;5:26. doi:10.1186/1754-6834-5-26.

24. Müller G, Várnai A, Johansen KS, Eijsink VGH, Horn SJ. Harnessing the potential of LPMO-containing cellulase cocktails poses new demands on processing conditions. Biotechnol Biofuels. 2015;8:187. doi:10.1186/ s13068-015-0376-y.

25. Hu JG, Arantes V, Pribowo A, Gourlay K, Saddler JN. Substrate factors that influence the synergistic interaction of AA9 and cellulases during the enzymatic hydrolysis of biomass. Energy Environ Sci. 2014;7(7):2308-15. doi:10.1039/C4EE00891J.

26. Sjöde A, Frölander A, Lersch M, Rødsrud G. Lignocellulosic biomass conversion by sulfite pretreatment. Patent EP2376642 B1. Borregaard AS; 2013.

27. Ståhlberg J, Divne C, Koivula A, Piens K, Claeyssens M, Teeri TT, et al. Activity studies and crystal structures of catalytically deficient mutants of cellobiohydrolase I from Trichoderma reesei. J Mol Biol. 1996;264(2):337-49. doi:10.1006/jmbi.1996.0644

28. Suurnäkki A, Tenkanen M, Siika-aho M, Niku-Paavola ML, Viikari L, Buchert J. Trichoderma reesei cellulases and their core domains in the hydrolysis and modification of chemical pulp. Cellulose. 2000;7(2):189-209. doi:10.1 023/A:1009280109519.

29. Várnai A, Tang C, Bengtsson O, Atterton A, Mathiesen G, Eijsink VGH. Expression of endoglucanases in Pichia pastoris under control of the GAP promoter. Microb Cell Fact. 2014;13:57. doi:10.1186/1475-2859-13-57.
30. Loose JSM, Forsberg Z, Fraaije MW, Eijsink VGH, Vaaje-Kolstad G. A rapid quantitative activity assay shows that the Vibrio cholerae colonization factor GbpA is an active lytic polysaccharide monooxygenase. FEBS Lett. 2014;588(18):3435-40. doi:10.1016/j.febslet.2014.07.036.

31. Bradford MM. A rapid and sensitive method for the quantitation of microgram quantities of protein utilizing the principle of protein-dye binding. Anal Biochem. 1976;72:248-54. doi:10.1016/0003-2697(76)90527-3.

32. Adav SS, Chao LT, Sze SK. Quantitative secretomic analysis of Trichoderma reesei strains reveals enzymatic composition for lignocellulosic biomass degradation. Mol Cell Proteom. 2012;11(7):M111-012419. doi:10.1074/ mcp.M111.012419.

33. Neta P, Huie RE. Free-radical chemistry of sulfite. Environ Health Perspect. 1985;64:209-17. doi:10.2307/3430011.

34. Zhou HF, Lou HM, Yang DJ, Zhu JY, Qiu XQ. Lignosulfonate to enhance enzymatic saccharification of lignocelluloses: role of molecular weight and substrate lignin. Ind Eng Chem Res. 2013;52(25):8464-70. doi:10.1021/ie401085k.

35. Wang ZJ, Zhu JY, Fu YJ, Qin MH, Shao ZY, Jiang JG, et al. Lignosulfonatemediated cellulase adsorption: enhanced enzymatic saccharification of lignocellulose through weakening nonproductive binding to lignin. Biotechnol Biofuels. 2013;6:156. doi:10.1186/1754-6834-6-156.

36. Chylenski P, Forsberg Z, Ståhlberg J, Várnai A, Lersch M, Bengtsson O, et al. Development of minimal enzyme cocktails for hydrolysis of 1 sulfite-pulped lignocellulosic biomass. J Biotechnol. 2017;246:16-23. doi:10.1016/j.jbiotec.2017.02.009.

37. Hu JG, Chandra R, Arantes V, Gourlay K, van Dyk JS, Saddler JN. The addition of accessory enzymes enhances the hydrolytic performance of cellulase enzymes at high solid loadings. Bioresour Technol. 2015;186:149-53. doi:10.1016/j.biortech.2015.03.055.

38. Wang GS, Pan XJ, Zhu JY, Gleisner R, Rockwood D. Sulfite pretreatment to overcome recalcitrance of lignocellulose (SPORL) for robust enzymatic saccharification of hardwoods. Biotechnol Prog. 2009;25(4):1086-93. doi:10.1002/btpr.206

39. Dimarogona M, Topakas E, Olsson L, Christakopoulos P. Lignin boosts the cellulase performance of a GH-61 enzyme from Sporotrichum thermophile. Bioresour Technol. 2012;110:480-7. doi:10.1016/j. biortech.2012.01.116.

40. Westereng B, Cannella D, Agger JW, Jørgensen H, Andersen ML, Eijsink VGH, et al. Enzymatic cellulose oxidation is linked to lignin by long-range electron transfer. Sci Rep. 2015;5:18561. doi:10.1038/srep18561.

41. Rodríguez-Zúñiga UF, Cannella D, Giordano RD, Giordano RDC, Jørgensen $\mathrm{H}$, Felby $\mathrm{C}$. Lignocellulose pretreatment technologies affect the level of enzymatic cellulose oxidation by LPMO. Green Chem. 2015;17(5):2896903. doi:10.1039/C4GC02179G.

42. Swan JM. Thiols, disulphides and thiosulphates—-some new reactions and possibilities in peptide and protein chemistry. Nature. 1957;180(4587):643-5. doi:10.1038/180643a0.

43. Yang SF. Destruction of tryptophan during aerobic oxidation of sulfite ions. Environ Res. 1973;6(4):395-402. doi:10.1016/0013-9351(73)90055-8.

\section{Submit your next manuscript to BioMed Central and we will help you at every step:}

- We accept pre-submission inquiries

- Our selector tool helps you to find the most relevant journal

- We provide round the clock customer support

- Convenient online submission

- Thorough peer review

- Inclusion in PubMed and all major indexing services

- Maximum visibility for your research

Submit your manuscript at www.biomedcentral.com/submit 